\title{
Application of the shakedown analysis in the elastic: plastic assessment of cracked plates
}

\author{
M. A. Belouchrani \\ Materials laboratory, E.M.P., BP 17 C Bordj El Bahri Alger, Algeria
}

\begin{abstract}
In this work, a new method in the elastic-plastic calculation of cracked plates, based on shakedown analysis, is presented. This method presents an interesting alternative to classical methods in the structure design, especially when the loading is variable. It permits, via a simple elastic calculation and a mathematical optimisation, the determination of a load domain situated between the elastic and the limit load domains, within which the loading can evolve arbitrarily, while insuring the reliability of the cracked structure versus the plastic ruin and the unstable crack propagation. Also, by taking into account the microstructure of the material and the residual stresses, this method allows the determination of a stress intensity factor corresponding to the shakedown state. This factor is comparable to the fatigue threshold and can be used in the crack admissibility criteria.
\end{abstract}

Keywords: shakedown, crack, notch, finite elements analysis, stress intensity factor, fatigue threshold.

\section{Introduction}

The structures used in the aeronautics, nuclear plants and naval yards are generally plane forms, originally, constituted of ductile material plates (metals and alloys) that could support irreversible plastic deformations before to break, and that even when they contain manufacture defects or cracks.

Cracks constitute the major problem of designers, because they can falsify completely the prediction of the conceived structure behavior, by accelerating their ruin through brutal propagation of these cracks.

When a crack is detected in a system, the designer undertakes an analysis, where he will have to explore the brutal rupture risk, the plastic ruin risk and the foreseeable evolution of the fissure. 
The most often, because of the geometrical singularity fathered by the crack, one uses the fracture mechanics, that has replaced the classical design methods.

Nevertheless, one knows that the fracture mechanics alone cannot insure that a crack is admissible; it attends only what happens at the vicinity of the crack tip (front), where the strong constraints and deformations can cause plastic yield of the material and therefore the propagation of the crack.

Criteria of defect admissibility of the fracture mechanics are naturally local, attached to event being able to happen at the crack tip. One knows also that even flawless, a structure cannot support unlimited loads, it finishes by bankrupting.

To take into account these two modes of ruin and to anticipate the stability and the security of the cracked structure, Belouchrani and Weichert [1][2], have proposed a new approach by the application of the shakedown theory, that finds its preferential application framework when the loading is variable. This new approach consists of an extension of the static shakedown theorem to the cracked structures.

The goal of this work is to present this new prediction method of the cracked plate security and reliability, by using the finite elements method and the nonlinear mathematical optimization.

The crack is assimilated to a sharp notch according to Neubers material block concept [3].

\section{Formulation of the shakedown theorem for a cracked body}

It has been suggested [1,2], that a cracked body shakes down with respect to a given loading history, if a time-independent state of residual stress $\rho^{\circ}(x)$ exists, such that for all times $\mathrm{t}>0$ :

$$
\begin{array}{cc}
\rho_{\mathrm{ij}, \mathrm{j}}^{\circ}=0 & \text { in } \Omega \\
\mathrm{n}_{\mathrm{j}} \rho_{\mathrm{ij}}^{\circ}=0 & \text { on } \Gamma_{\sigma} \\
\mathrm{F}\left(\sigma_{\mathrm{ij}}^{\mathrm{c}}(\mathrm{t})+\rho_{\mathrm{ij}}^{\circ}, \sigma_{\mathrm{y}}\right)<0 & \text { in } \Omega
\end{array}
$$

With a supplementary condition imposed on the admissible length of a typical micro-crack in the material

$$
\mathrm{a}_{\lim }<\mathrm{a}_{\mathrm{c}}
$$

Here, $\mathbf{F}$ is the plastic yield surface assumed of Von-Mises type, convex by definition, $\sigma_{\mathrm{y}}$ is the yield stress and $\mathrm{a}_{\text {lim }}$ is the largest admissible crack length determined by means of shakedown analysis. In inequality $(3), \sigma^{c}(x, t)$ is the time-dependent stress state for a purely elastic comparison problem, differing from the original problem only by the fact that the material reacts purely elastically with the same elastic moduli as for the elastic part of the material law in the original problem. For the Lemaitre-Chaboche model [4] adopted for ductile fracture, $\mathrm{a}_{\text {lim }}$ is given by $[1,2]$

$$
\mathrm{a}_{\lim }=\mathrm{a}_{0}+\left[\frac{\mathrm{m}+1}{\mathrm{~m}} \frac{1}{\mathrm{~K}} \frac{\alpha}{\alpha-1} \int_{\Omega} \frac{1}{2}\left(\rho_{\mathrm{ij}}^{\circ} \mathrm{L}_{\mathrm{ijk} 1} \rho_{\mathrm{k} 1}^{\circ}\right) \mathrm{d} \Omega\right]^{\mathrm{m} /(\mathrm{m}+1)}
$$


Here, $a_{0}$ is the initial crack length, $\mathbf{L}$ is the positive definite and timeindependent tensor of elastic moduli, $\mathrm{m}$ and $\mathrm{K}$ are material constants characterizing the R-curve parameters and $\alpha$ is the shakedown safety factor.

As mentioned before, the problem of stress singularity of the elastic stress field deserves special attention for the application of the shakedown theorem to cracked structures. In this case, no time-independent field of residual stresses $\rho^{\circ}(\mathrm{x})$ satisfying inequality (3) can be found and classical shakedown theory does not deliver comprehensive results, even for loads for which limit states physically exist. We bypass this problem by assimilating the crack tip to a notch, following the concept of material block introduced by [3] and used in the same spirit as in the present work by [5].

So, following [6], the stress distribution in the neighborhood of the root of the notch given by

$$
\mathrm{r}_{\mathrm{f}}=\mathrm{r}+\mathrm{n} \varepsilon
$$

with, according to figure $1, \mathrm{r}_{\mathrm{f}}$ as the effective notch root radius, $\varepsilon$ as the length of the Neuber material block (assumed to be a material constant), and $\mathrm{n}$ as the factor depending on the loading mode. The factor $n$ is equal to 2 in mode I. Following this concept, the effective notch radius is equal to the original notch radius augmented of $\mathrm{n}$ times the dimension of the Neuber material block.

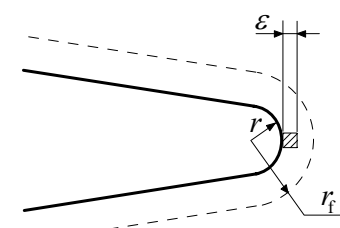

Figure 1: $\quad$ Modified notch and crack.

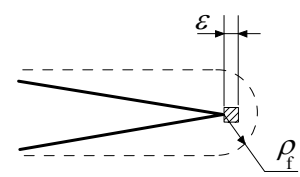

In the case of a sharp crack, the radius at the root of the effective crack, denoted $\rho_{\mathrm{f}}$, can be obtained just by putting $\mathrm{r}=0$ in Eqn. (6)

$$
\rho_{\mathrm{f}}=\mathrm{n} \varepsilon
$$

Eqn. (7) indicates implicitly that the crack can be treated as a notch with $\rho_{\mathrm{f}}$ radius. Physically, Neubers material block may be explained as being the sum of the minimum number of individual microscopic material particles (such as grains in polycrystalline metals). The properties of which may differ from each other, but in average they should have the property of the macroscopic material. In [5], $\rho_{\mathrm{f}}$ is put to be about ten times the size of a grain, for the mode I loading. Following this suggestion we write

$$
\varepsilon \approx 5 \xi
$$

\section{Shakedown safety factor}

We consider an elastic-plastic plate, subjected to uniaxial loads $\mathrm{P}(\mathrm{t})$. The values of $\mathrm{P}(\mathrm{t})$ vary arbitrarily with time $\mathrm{t}$, but remain between prescribed loads $\mathrm{P}_{\min }$ 
and $\mathrm{P}_{\max }$. One then looks for the maximum value of the load factor $\alpha$, such that the plate will shake down under the load $\alpha \mathrm{P}(\mathrm{t})$. This load factor will be called the shakedown load factor $\alpha_{\mathrm{SD}}$ and can be determined as solution of the following optimization problem

$$
\alpha_{\mathrm{SD}}=\max _{\alpha, \rho^{\circ}} \alpha
$$

with the subsidiary conditions

$$
\begin{aligned}
& \rho_{\mathrm{ij}, \mathrm{j}}^{\circ}=0 \quad \text { in } \Omega \\
& \mathrm{n}_{\mathrm{j}} \rho_{\mathrm{ij}}^{\circ}=0 \quad \text { on } \Gamma_{\sigma} \\
& \mathrm{F}\left(\alpha \sigma^{\mathrm{c}}(\mathrm{P})+\rho^{\circ}, \sigma_{\mathrm{y}}\right)<0 \quad \text { in } \Omega \quad \forall \mathrm{P} \in\left[\mathrm{P}_{\min }, \mathrm{P}_{\max }\right] \\
& \mathrm{a}_{\lim }=\mathrm{a}_{0}+\left[\frac{\mathrm{m}+1}{\mathrm{~m}} \frac{1}{\mathrm{~K}} \frac{\alpha}{\alpha-1} \int_{\Omega} \frac{1}{2}\left(\rho_{\mathrm{ij}}^{\circ} \mathrm{L}_{\mathrm{ijkl}} \rho_{\mathrm{kl}}^{\circ}\right) \mathrm{d} \Omega\right]^{\mathrm{m} /(\mathrm{m}+1)}<\mathrm{a}_{\mathrm{c}}
\end{aligned}
$$

\section{Fatigue threshold and influence of the microstructure}

In what follows, the classical concept of existence of a threshold $\mathrm{K}_{\mathrm{S}}$ for the stress intensity factor $K_{I}$ in opening mode $\mathrm{I}$ is used.

$$
\mathrm{K}_{\mathrm{I}}=\sigma \sqrt{\pi \mathrm{a}}
$$

Therefore, it is assumed that the micro-crack propagation does not occur if

$$
\mathrm{K}_{\mathrm{I}}<\mathrm{K}_{\mathrm{S}}
$$

and the material state is safe against failure by fatigue. Among other parameters, the fatigue threshold is influenced by the microstructure of the material. Generally, it is admitted that $\mathrm{K}_{\mathrm{S}}$ increases with the size of the grain as has been observed on ferritic steels by [7-9]. It has been suggested that the dependence between $\mathrm{K}_{\mathrm{S}}$ and $\xi^{1 / 2}$ ( $\xi$ is the diameter of the grain) are related by a linear function [7-9]

$$
\mathrm{K}_{\mathrm{S}}=\mathrm{a}_{1}+\mathrm{b}_{1} \xi^{1 / 2}
$$

where the dimensions of $\mathrm{K}_{\mathrm{S}}$ and $\xi$ are, respectively, [MPa.m ${ }^{1 / 2}$ ] and $[\mathrm{m}]$. Here, $a_{1}$ and $b_{1}$ are material constants.

\section{Shakedown stress intensity factor $K_{S D}$}

With the shakedown load factor $\alpha_{\mathrm{SD}}$ computed for a cracked plate loaded in mode I, we will compute the stress intensity factor (Eqn. (14)) corresponding to the shakedown state by [10]

$$
\mathrm{K}_{\mathrm{SD}}=\alpha_{\mathrm{SD}} \mathrm{P} \sqrt{\pi \mathrm{a}_{\lim }}
$$




\section{Numerical examples}

Here, the finite element method is used combined with mathematical programming method to maximize the load factor under the subsidiary conditions (10)-(13) such that the yield criterion $\mathbf{F}$ is not violated in any point of the plate and that the admissible crack length $\mathrm{a}_{\lim }$ remains inferior to its critical value $\mathrm{a}_{\mathrm{c}}$. The resolution of this mathematical programming problem is performed using the code LPNLP [11] that is based on an augmented Lagrangian method and the BFGS-algorithm. For the solution one needs:

- the solution of the purely elastic comparison problem in the sense of shakedown analysis,

- the construction of a time-independent residual stress field.

To this end, we use the finite element force method based on the principle of minimum complementary energy [12]. This approach uses stress functions for the construction of the complementary energy function and represents an algebraic dual to the finite element displacement method. This method has been used by [13] for the study of limit and shakedown analysis of two-dimensional structures.

\subsection{Shakedown loads domain:}

We consider a rectangular cracked plate, subjected to uniform loading (fig.2):

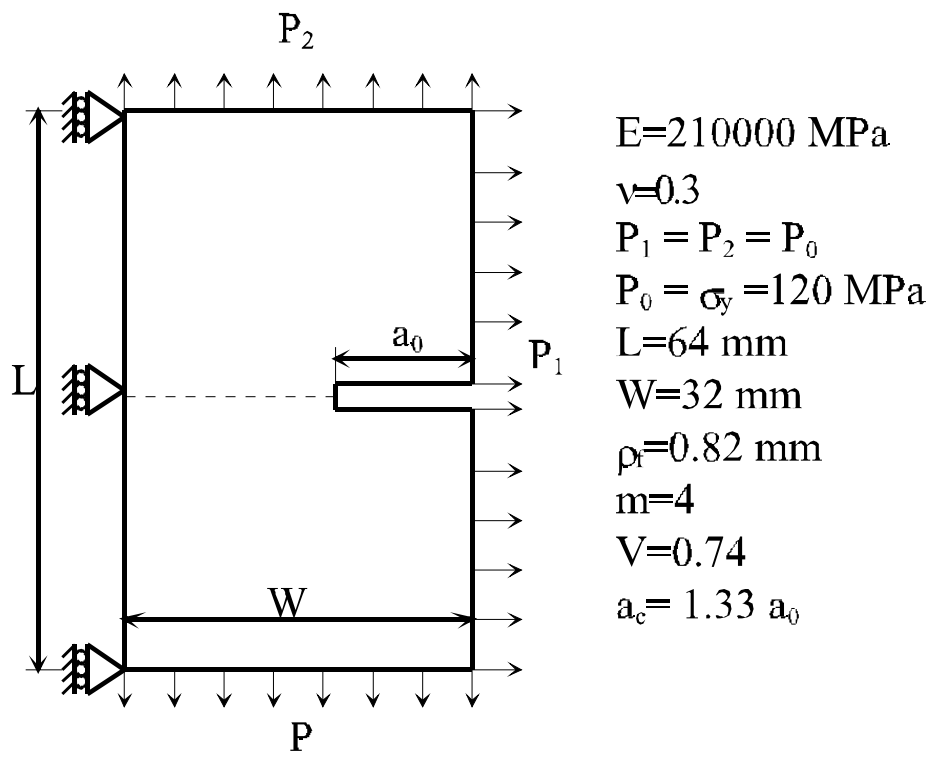

Figure 2: Rectangular plate with lateral crack. 
The obtained results (fig. 3) show that the safety load is reduced in the presence of crack; this reduction depends on the crack length. The load $\mathrm{P}_{2}$ amends adversely the domain of load and reduces the limits of the load obtained. While under the load $\mathrm{P}_{1}$, the influence of the crack is lesser because the stress concentration is less important, and is situated on crack lips, not in front of the crack tip.

Figure 4 shows well that in the case of a cracked plate, the dimensioning based on the limit analysis is not recommended if the applied loads could vary in an independent way.

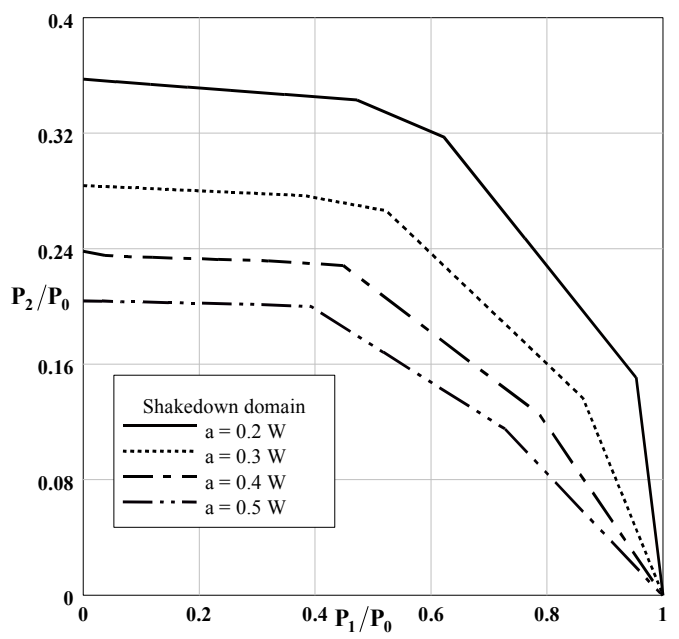

Figure 3: Shakedown domain.

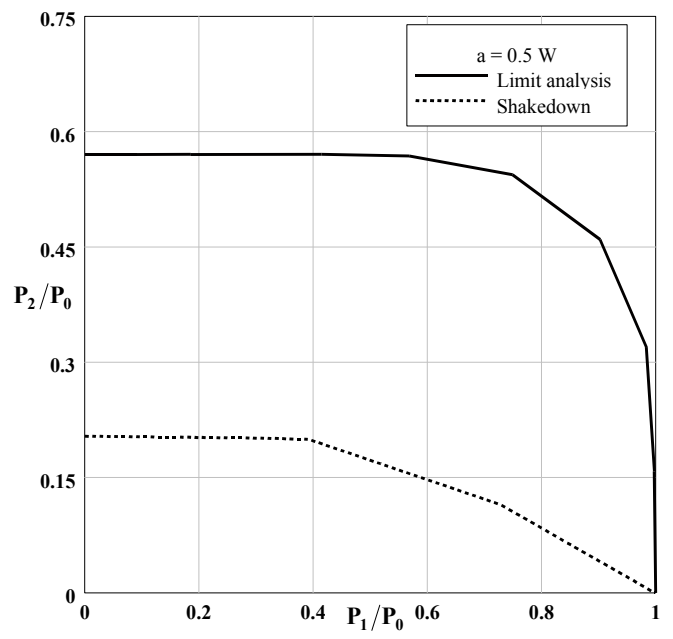

Figure 4: Shakedown and load limits domains. 


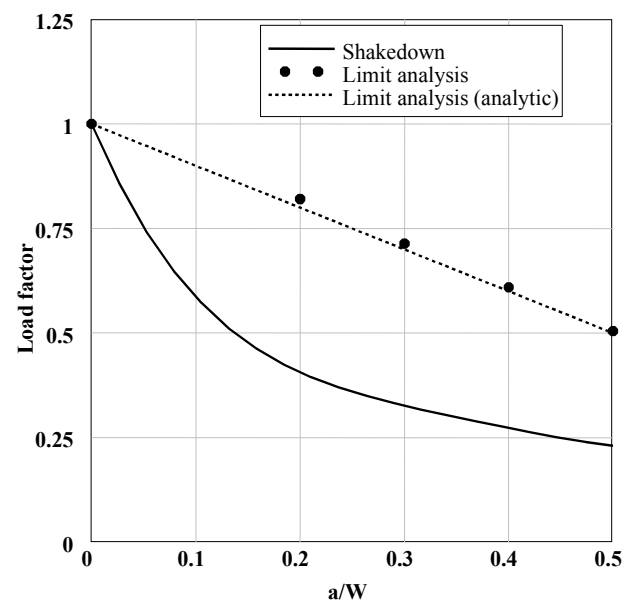

Figure 5: Influence of the ratio a/W on the load factor.

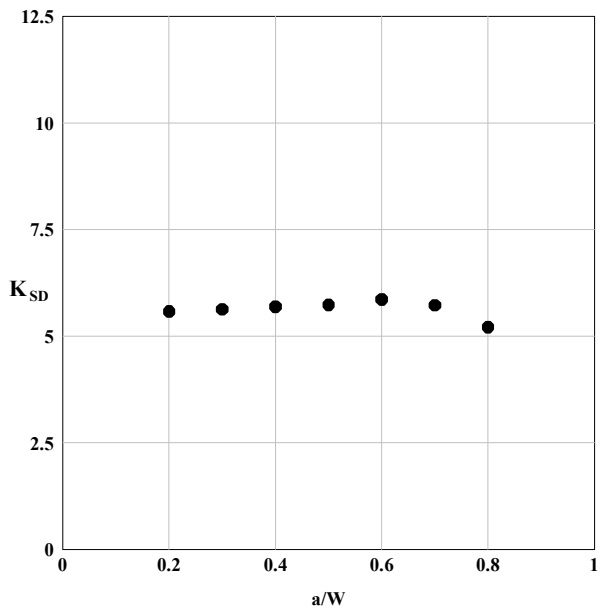

Figure 6: Independence of $\mathrm{K}_{\mathrm{SD}}$ with a/W.

Figure 5 shows that for the cracked plate subjected to the load $\mathrm{P}_{2}$, the value of the limit load values agrees with the analytical ones.

\subsection{Shakedown stress intensity factor $K_{\text {SD }}$}

We have computed the stress intensity factor at the shakedown state for different crack lengths, the obtained results (fig 6), show that this factor $\mathrm{K}_{\mathrm{SD}}$ is crack length independent, and it can be considered as the safety parameter against the cracked structure ruin, by plasticity and crack propagation for the mode I of loading. 


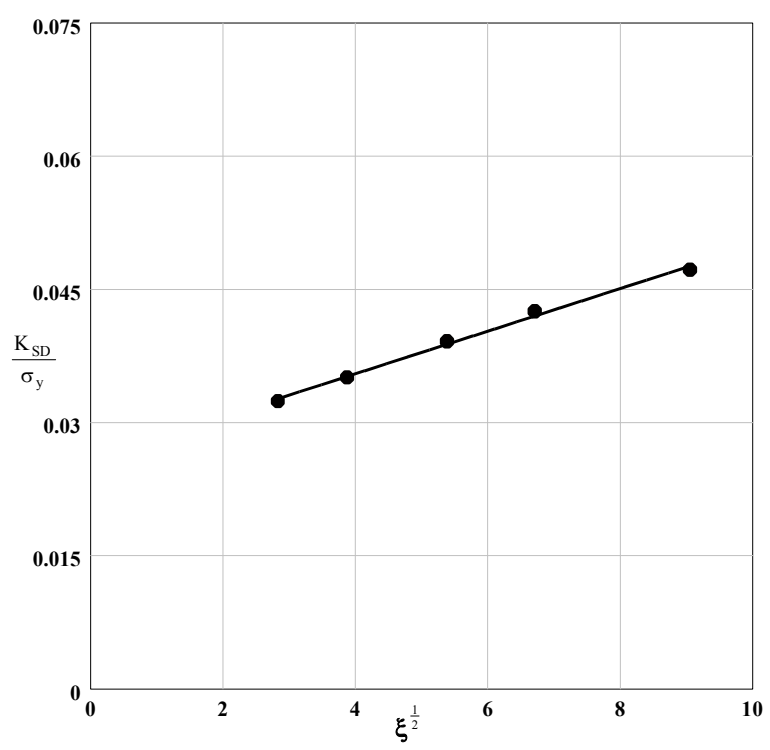

Figure 7: $\quad$ Relation between $\mathrm{K}_{\mathrm{SD}}$ and $\xi^{1 / 2}$.

We have then studied the influence of the grain size on the shakedown stress intensity factor $\mathrm{K}_{\mathrm{SD}}$, figure 7 shows that the ratio $\mathrm{K}_{\mathrm{SD}} / \sigma_{\mathrm{y}}$ varies linearly with $\xi^{1 / 2}$.

$$
\frac{\mathrm{K}_{\mathrm{SD}}}{\sigma_{\mathrm{y}}}=\mathrm{a}+\mathrm{b} \xi^{1 / 2} .
$$

By comparing this equation with the equation giving the fatigue threshold, one notes that the yield stress influences the shakedown stress intensity factor. This can be explained by the fact that the shakedown intensity factor is computed by taking into account the yield stress and the largest admissible crack length.

\subsection{Comparison of $K_{\mathrm{SD}}$ and the fatigue threshold values for some materials}

To validate the proposed approach, a comparison is made between the values of $\mathrm{K}_{\mathrm{SD}}$ computed in the case of a rectangular plate solicited in mode $\mathrm{I}$, the fatigue threshold $\mathrm{K}_{\mathrm{S}}$ given by [7] and the shakedown stress intensity factor $\mathrm{K}_{\text {sh }}$ given by [5] for some materials. The characteristics of these materials are given in the Table 1 .

According to the results given in the Table 2, one remarks that the values of $\mathrm{K}_{\mathrm{SD}}$ agree with the values of $\mathrm{K}_{\mathrm{sh}}$ given by [5]. On the other hand, one notices a disparity with the fatigue threshold $\mathrm{K}_{\mathrm{S}}$ given by [7] for materials $\mathrm{A}$ and $\mathrm{E}$. However, the results indicate that indeed $\mathrm{K}_{\mathrm{SD}}$ can be considered as fatigue threshold. 
Table 1: $\quad$ Diameter of the grain and mechanical material data.

\begin{tabular}{|c|c|c|c|}
\hline Material & Designation & $\xi(\mu \mathrm{m})$ & $\sigma_{\mathrm{y}}(\mathrm{MPa})$ \\
\hline Docol 350 & A & 8 & 260 \\
\hline SS 141147 & B & 15 & 185 \\
\hline HP steel & C & 29 & 210 \\
\hline HP steel & D & 45 & 160 \\
\hline HP steel & E & 82 & 120 \\
\hline
\end{tabular}

Table 2: $\quad$ Fatigue threshold and shakedown stress intensity factors.

\begin{tabular}{|c|c|c|c|}
\hline Material & $\mathrm{K}_{\mathrm{S}}$ & $\mathrm{K}_{\mathrm{sh}}$ & $\mathrm{K}_{\mathrm{SD}}$ \\
\hline $\mathrm{A}$ & 5.4 & 8.9 & 8.43 \\
\hline $\mathrm{B}$ & 6.0 & 7.6 & 6.49 \\
\hline $\mathrm{C}$ & 6.2 & 9.5 & 8.22 \\
\hline $\mathrm{D}$ & 6.7 & 8.1 & 6.8 \\
\hline $\mathrm{E}$ & 8.2 & 7.8 & 5.73 \\
\hline
\end{tabular}

More, knowing that the relationship existing between the yield stress and the diameter of the grain has the following form $[7,8]$ :

$$
\sigma_{\mathrm{y}}=\mathrm{c}+\mathrm{d} \xi^{-\frac{1}{2}}
$$

$\sigma_{y}$ increases when the diameter of the grain decreases and since the residual stress intensity increases with the increase of the elastic limit, one can say, considering the equation (16), that disparities observed between $\mathrm{K}_{\mathrm{SD}}$ and $\mathrm{K}_{\mathrm{S}}$ values are mainly caused by the residual stresses.

One concludes that the computed stress intensity factor can be considered as a fatigue threshold taking into account the residual stresses.

\section{Conclusion}

In this work, we have presented a new method in the prediction of the inelastic cracked structures failure by the application of the shakedown analysis. This new method presents several advantages, among which, the facility of computation since one undertakes only an elastic calculation. Also, it allows going more far than the elastic limit in the structures design. We can also compute the fatigue threshold using this method.

\section{References}

[1] Belouchrani M. A., Contribution to the shakedown analysis of inelastic cracked structures, PhD Thesis, University of Lille, (1997). 
[2] Belouchrani M. A. and Weichert D., An extension of the static shakedown theorem to inelastic cracked structures, Int. J. Mech. Sci., 41, 163-177, (1998).

[3] Neuber H., Über die Berücksichtigug der Spannungskonzentration bei Festigkeitsberechnungen, Konstruktion 20 (7), 245-251, (1968).

[4] Lemaitre J. and Chaboche J. L., Mécanique des matériaux solides, Dunod, Paris, (1985).

[5] Huang Y. and Stein E., Shakedown of a cracked body consisting of kinematic hardening material, Eng. Frac. Mech, 54, 1, 107-112, (1996).

[6] Creager M., Master Thesis, Lehigh University, (1966).

[7] Wasen J., Hamberg K. and Karlsson B., The influence of Grain Size and Fracture Surface Geometry on the Near-threshold Fatigue Crack Growth in Ferritic Steels, Materials Science and Engineering A, 102, 217-226, (1988).

[8] Xu-Dong Li and Edwards L., Theoretical Modelling of Fatigue Threshold for Aluminium Alloys, Eng. Frac. Mech., 54, 35-48, (1996).

[9] Radaj D. and Zhang S., On the relation between notch stress and crack stress intensity in plane shear and mixed mode loading, Eng. Frac. Mech., 44, N5, 691-704, (1993).

[10] Belouchrani M. A., Weichert D. and Hachemi A., Fatigue threshold computation by shakedown theory, Mech. Resea. Comm., vol. 27, $\mathrm{N}^{\circ} 3$, pp. 287-293, (2000).

[11] Pierre D. A. and Lowe M. J., Mathematical programming via Augmented Lagrangians, London: Addison-Wesley, (1975).

[12] Gallagher R. H. and Dhalla A. K., Direct flexibility finite element elastoplastic analysis, Englewood Cliffs, New Jersey, USA, (1975).

[13] Gross-Weege J. and Weichert D., Elastic-plastic shells under variable mechanical and thermal loads, Int. J. Mech. Sci., 34, 863-880, (1992). 